\title{
PERSEPSI PETANI TERHADAP USAHATANI STEVIA (Studi Kasus di Desa Mekarsari, Kecamatan Cikajang, Kabupaten Garut)
}

\author{
FARHAN MUHAMAD FACHRI*, HEPI HAPSARI, YAYAT SUKAYAT \\ *Program Studi Agribisnis, Fakultas Pertanian, Universitas Padjadjaran ${ }^{1,2,3}$ \\ *Email: farhanmarkum61@gmail.com
}

\begin{abstract}
ABSTRAK
Penelitian ini akan melihat karakteristik petani, bagaimana persepsi petani di Desa Mekarsari, serta usahatani stevia selama satu tahun agar nantinya bisa diketahui apakah usahatani stevia di Desa Mekarsari baik atau dan apakah usahatani stevia lebih baik dilanjutkan atau tidak jika dilihat dari persepsi petani penggarap dan buruh tani. Desain yang digunakan dalam penelitian ini adalah kuantitatif dengan metode statistika deskriptif dengan alat bantu analisis nilai rataan skor yang dipresentasikan dengan tabulasi silang. Hasil analisis menunjukkan bahwa usahatani stevia sudah menguntungkan selama satu tahun, serta persepsi petani di Desa Mekarsari mayoritas baik terhadap usahatani stevia dilihat dari semua karakteristik petani.
\end{abstract}

Kata kunci: Persepsi, Usahatani, Stevia

\section{ABSTRACT}

This research will look at the characteristics of farmers, how the perception of the farmers in the village of Mekarsari, as well as farming stevia for one year so that later can be known whether stevia farming Village in Mekarsari good or stevia farming and what better continued or not if viewed from the perception of sharecroppers and farm laborers. The design used in this research is quantitative descriptive statistical methods with value analysis tools rataan score presented with cross-tabulations. The results of the analysis indicate that stevia is already profitable farming for a year, as well as the perception of the majority of the farmers in the village of Mekarsari well against stevia farming views of all characteristics of the farmers.

Keywords: Perception, Farming, Stevia

\section{PENDAHULUAN}

Salah satu tanaman pemanis selain tebu adalah Stevia rebaudiana. Daun tanaman ini mengandung bahan pemanis yang disebut steviosida dan rebaudiosida, yang tingkat kemanisannya 300 kali daripada sukrosa yang terkandung pada tanaman tebu (Geuns, 2003). Keunggulan stevia dibandingkan sukrosa atau gula tebu adalah dapat mengurangi resiko serangan penyakit diabetes.

Pada tahun 2013, total konsumsi stevia di dunia menurut Zenith
Internasional (Gambar 1) adalah sebesar 4.100 ton, dengan Asia Pasifik sebagai daerah dengan jumlah konsumsi terbesar yaitu 1.353 ton, kemudian kedua terbesar yaitu Amerika Utara dengan jumlah konsumsi sebesar 1.230 ton, ketiga terbesar adalah Amerika Selatan dengan konsumsi sebesar 1.025 ton, Eropa adalah benua yang paling sedikit jumlah konsumsinya yaitu sebesar 451 ton, di daerah lain selain yang telah disebutkan sebesar 41 ton. 


\section{GLOBAL STEVIA MARKET BY REGION 2013}

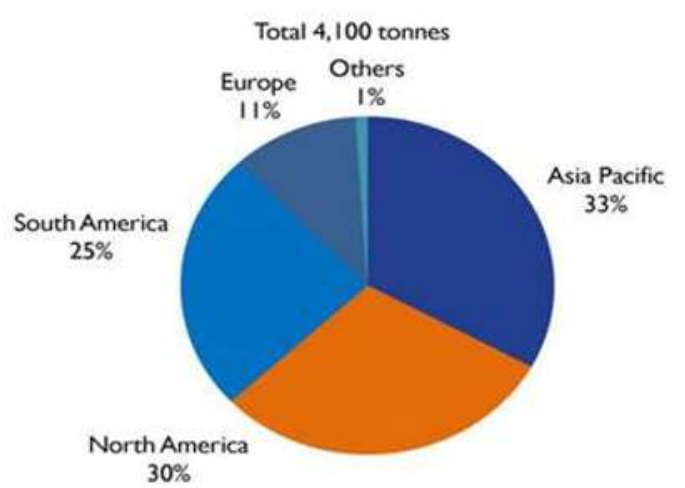

Sumber: Zenith International, 2013

Gambar 1. Persentase Konsumsi Stevia di Dunia Tahun 2013

Di Provinsi Jawa Barat, khususnya di Desa Mekarsari, Kecamatan Cikajang, Kabupaten Garut, sedang dibudidayakan stevia oleh sebagian petani di bekas kebun teh Pamegatan. Para petani yang menanam stevia di Desa tersebut adalah petani binaan Kepala Desa Mekarsari yaitu Budiman, S.Sos.

Pemasarannya pun sudah jelas karena bekerjasama dengan perusahaan dari negara Jepang yaitu PT. Tokinoto Agro Utama dengan sistem kontrak. PT Tokinoto Agro Utama membuat kontrak dengan memberikan bibit stevia secara gratis dan pengarahan kepada petani dalam budidaya stevia, dan hasil panen seluruhnya harus dijual kepada PT Tokinoto Agro Utama. Tim perusahan dari Jepang mengatakan bahwa kualitas tanaman stevia di Desa Mekarsari Kecamatan Cikajang ini merupakan salah satu kualitas terbaik di dunia.
Selain PT Tokinoto Agro Utama, terdapat juga PT Agro Jabar yang bekerjasama dengan petani stevia di Desa Mekarsari. PT Agro Jabar yang membeli stevia dari petani setempat untuk dijadikan bahan produk stevia cair dengan merk dagang Steviamore dan juga dijual menjual stevia kering kepada perusahaan lain yang membutuhkan stevia sebagai bahan olahan produknya. Kontrak petani dan PT Agrojabar adalah dengan meminjamkan dana kepada para petani, kemudian petani mengembalikan dana pinjaman setelah menjual kepada PT Agrojabar.

PT Agro Jabar sejak awal tahun 2018 berencana untuk mengembangkan lagi luas lahan yang ditanami stevia hingga seluas 100 hektar di lahan Pamegatan. karena itu akan banyak sekali petani mitra yang dibutuhkan untuk pengembangan stevia di lahan tersebut.

Perlakuan pasca panen stevia yaitu daun hasil panen stevia dikeringkan dengan 
alat pengering teh kemudian daun kering stevia diperlakukan dan dikemas dengan perlakuan yang sama seperti daun teh kering. Kemiripan pengolahan pasca panen stevia dengan teh yang dulu petani lakukan di desa tersebut ditambah dengan pemasaran dan harganya yang sudah jelas bisa menambah keinginan petani untuk berusahatani stevia.

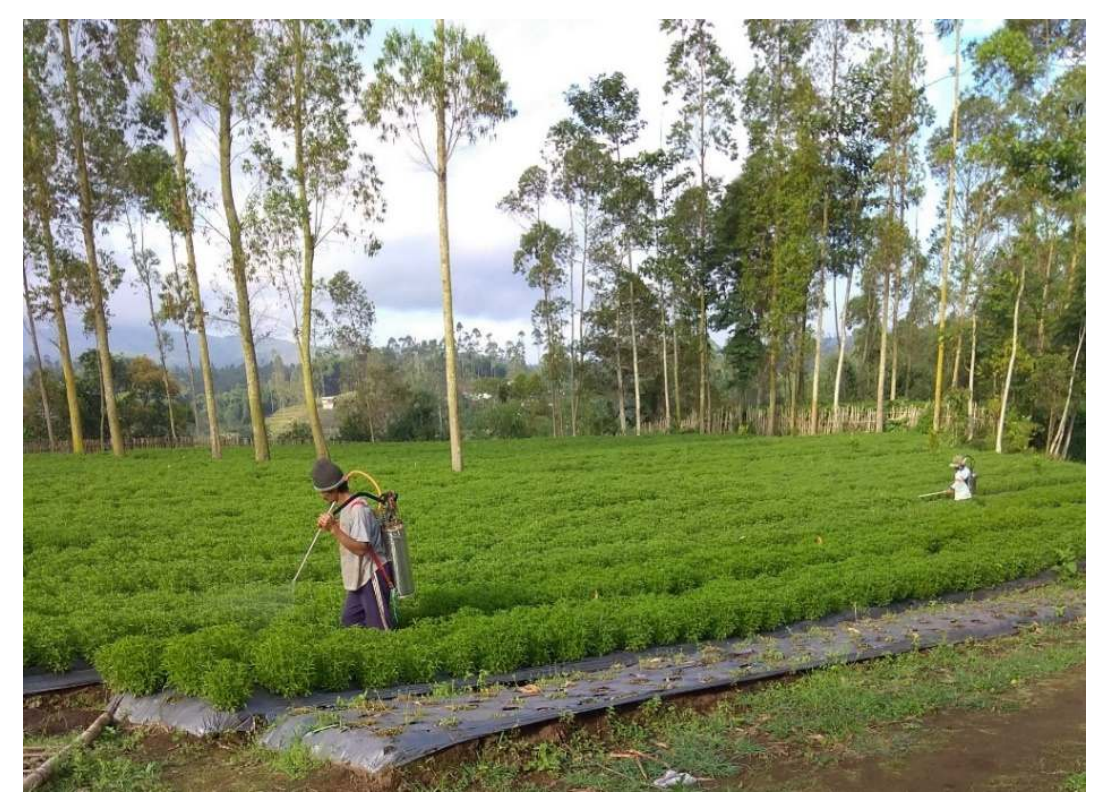

Gambar 2. Lahan Stevia di Desa Mekarsari

Di sisi lain, komoditas stevia untuk bisa dikonsumsi butuh pengolahan yang rumit dan menjualnya pun tidak bisa sembarangan sehingga petani berpikir lagi apakah stevia merupakan komoditas yang menguntungkan dari berbagai aspek. Keinginan para petani tersebut untuk menanam stevia atau menolak stevia disebabkan oleh persepsi para petani di Desa Mekarsari terhadap usahatani komoditas stevia, baik petani yang telah berusahatani stevia maupun petani yang telah melihat petani lain yang telah berusahatani stevia.
Keinginan para petani tersebut untuk menanam stevia atau menolak stevia disebabkan oleh persepsi para petani di Desa Mekarsari terhadap usahatani komoditas stevia, baik petani yang telah berusahatani stevia maupun petani yang telah melihat petani lain yang telah berusahatani stevia.

Menurut Jalaludin Rakhmat dalam bukunya Psikologi Komunikasi (2004:51) bahwa persepsi merupakan pengalaman tentang objek, atau hubungan yang diperoleh dengan menyimpulkan informasi dan menafsirkan pesan. Sesuai dengan teori 
tersebut, persepsi petani di Desa Mekarsari terhadap usahatani stevia terbentuk setelah para petani tersebut melakukan usahatani stevia dan melakukan penilaian dari Menurut Soekartawi (1988) umur, pendidikan, pengalaman bertani, dan pendapatan merupakan faktor yang dapat mempengaruhi persepsi petani terhadap suatu objek dan dalam penelitian ini objeknya adalah usahatani komoditas stevia.

Berkaitan dengan penelitian ini maka faktor yang dapat mempengaruhi persepsi petani terhadap usahatani komoditas stevia, yaitu: umur, pendidikan formal, pendidikan nonformal, pengalaman bertani, dan pendapatan dari usahatani stevia.

Persepsi petani dapat menjadi salah satu dasar pengambilan keputusan dalam berusahatani stevia bagi para petani di Desa Mekarsari yang sebelumnya menanam komoditas sayuran dan teh, sehingga persepsi ini menarik untuk diteliti sebagai bahan pertimbangan dalam menentukan kebijakan yang mendukung pengembangan usahatani stevia di Desa Mekarsari.

Berdasarkan latar belakang tersebut, maka dapat diidentifikasikan masalah dari penjelasan diatas adalah: (1) Bagaimana karakteristik petani stevia di Desa Mekarsari. (2) Bagaimana persepsi petani terhadap usahatani stevia di Desa Mekarsari. (3) Bagaimana hubungan antara karakteristik petani stevia dan persepsi beberapa aspek, yaitu: keuntungan relatif, tingkat kesesuaian, tingkat kerumitan, tingkat kemudahan untuk dicoba, dan tingkat kemudahan dilihat hasilnya.

petani terhadap usahatani stevia. Tujuan yang hendak dicapai dari penelitian ini adalah: (1) Mengidentifikasi karakteristik petani stevia di Desa Mekarsari. (2) Mengetahui persepsi petani terhadap usahatani stevia di Desa Mekarsari. (3) Mengetahui hubungan antara karakteristik petani dan persepsi petani terhadap usahatani stevia.

\section{METODE PENELITIAN}

Desain penelitian yang digunakan dalam penelitian ini adalah desain kuantitatif dengan metode statistika deskriptif. Data primer diperoleh dari observasi, wawancara, dan kuesioner. Sedangkan data sekunder diperoleh dari Badan Pusat Statistik, data perusahaan, penelitian terdahulu, dan berbagai literatur yang berkaitan dengan topik penelitian. Alat analisis yang digunakan adalah analisis rataan skor yang dipresentasikan dengan analisis tabulasi silang. Analisis tabulasi silang atau crosstabs digunakan untuk menghitung frekuensi dan persentase dua atau lebih variabel secara sekaligus dengan cara menyilangkan variabel-variabel yang dianggap berhubungan sehingga makna hubungan dua .variabel mudah dipahami secara deskriptif (Santoso, 2001). 


\section{HASIL PENELITIAN}

\section{Karakteristik Petani Penggarap dan Buruh Tani}

\section{Umur}

Tabel 1. Persentase Umur

\begin{tabular}{llcccc}
\hline Karakteristik & \multirow{2}{*}{ Kategori } & \multicolumn{2}{c}{ Buruh tani } & \multicolumn{2}{c}{ Petani penggarap } \\
\cline { 3 - 6 } Petani & & Responden $(\mathrm{n})$ & Persen (\%) & Responden (n) & Persen (\%) \\
\hline Umur & Produktif & 26 & $86 \%$ & 6 & $100 \%$ \\
& Tidak produktif & 4 & $14 \%$ & 0 & $0 \%$ \\
\hline
\end{tabular}

Tabel 1 menunjukkan bahwa di Desa Mekarsari terdapat lebih banyak buruh tani stevia berusia produktif (93\%) daripada petani berusia tidak produktif (7\%). Petani penggarap di Desa Mekarsari 100\% berusia produktif. Mantra (2004) menyatakan bahwa umur produktif secara ekonomi dibagi menjadi 3 klasifikasi, yaitu kelompok umur 0-14 tahun merupakan usia belum produktif, kelompok umur 15-64 tahun merupakan kelompok usia produktif, dan kelompok umur di atas 65 tahun merupakan kelompok usia tidak lagi produktif.

\section{Tingkat Pendidikan}

Tabel 2. Persentase Tingkat pendidikan

\begin{tabular}{llcccc}
\hline Karakteristik & \multicolumn{1}{c}{ Kategori } & \multicolumn{2}{c}{ Buruh tani } & \multicolumn{2}{c}{ Petani penggarap } \\
\cline { 2 - 5 } Petani & \multicolumn{1}{c}{ Responden (n) } & Persen (\%) & Responden (n) & Persen (\%) \\
\hline Pendidikan & Tidak sekolah-Tidak tamat & 7 & $24 \%$ & 0 & $0 \%$ \\
& SD & 16 & $53 \%$ & 3 & $50 \%$ \\
& Tamat SD-Tidak tamat SMP & 4 & $13 \%$ & 2 & $33 \%$ \\
& Tamat SMP-Tidak tamat & 1 & $3 \%$ & 0 & $0 \%$ \\
& SMA & 2 & $7 \%$ & 1 & $17 \% \%$ \\
\hline
\end{tabular}

Tingkat pendidikan petani stevia di Desa Mekarsari didominasi oleh buruh tani dengan tingkat pendidikan tamat SD hingga tidak tamat SMP (50\%), kemudian terbanyak kedua adalah petani dengan tingkat pendidikan tidak sekolah hingga tidak tamat SD (24\%), setelah itu terbanyak ketiga adalah petani dengan tingkat pendidikan tamat SMP hingga tidak tamat SMA (13\%), keempat adalah tingkat pendidikan petani yang tamat perguruang tinggi $(10 \%)$, dan terakhir paling sedikit adalah petani yang tingkat pendidikannya tamat SMA (3\%). Petani penggarap di Desa Mekarsari mayoritas adalah tamat SD hingga tidak tamat SMP (50\%), kemudian tamat SMP sampai tidak tamat SMA (33\%), kemudian tamat perguruan tinggi (17\%), untuk yang tamat SMA dan tidak sekolah tidak ada. Tingkat pendidikan formal responden akan mempengaruhi pola pikir terhadap pengelolaan usahataninya dan 
permasalahan yang dihadapi. diungkapkan Alisa (2007) menyatakan bahwa semakin tinggi pendidikan formal, akan semakin tinggi pula kemampuannya untuk menerima, menyaring, dan menerapkan inovasi yang dikenalkan kepadanya.

\section{Pengalaman Bertani}

Tabel 3. Persentase Pengalaman Bertani

\begin{tabular}{llcccc}
\hline \multirow{2}{*}{$\begin{array}{c}\text { Karakteristik } \\
\text { Petani }\end{array}$} & \multirow{2}{*}{ Kategori } & \multicolumn{2}{c}{ Buruh tani } & \multicolumn{2}{c}{ Petani penggarap } \\
\cline { 2 - 6 } & & Responden (n) & Persen (\%) & Responden (n) & Persen (\%) \\
\hline Lama & Rendah & 12 & $40 \%$ & 15 & $50 \%$ \\
bertani & Sedang & 11 & $37 \%$ & 10 & $33 \%$ \\
& Tinggi & 7 & $23 \%$ & 5 & $17 \%$ \\
\hline
\end{tabular}

Pengalaman bertani yang dilakukan oleh petani stevia di Desa Mekarsari adalah pengalaman bertani dari awal mereka bertani hingga sekarang bertani stevia. Faktor fungsional yang mempengaruhi persepsi berasal dari kebutuhan, pengalaman masa lalu dan hal-hal lain yang termasuk ke dalam faktor pribadi (Rakhmat, 2004). Buruh tani stevia di Desa Mekarsari mayoritas sudah bertani dengan lama bertani yang rendah atau 7-19 tahun (40\%), kemudian yang lama bertaninya sedang atau 20-32 tahun (37\%), dan paling sedikit petani dengan lama bertani yang tinggi atau di atas 33-43 tahun (23\%). Petani penggarap di Desa Mekarsari mayoritas memiliki pengalaman bertani yang rendah atau 17-25 tahun (50\%), kemudian yang sedang atau 26-32 tahun (33\%) dan tinggi atau 33-40 tahun (17\%). Semakin banyak pengalaman yang diperoleh petani maka diharapkan produktivitas petani akan semakin tinggi, sehingga dalam mengusahakannya usahatani akan semakin baik dan sebaliknya jika petani tersebut belum atau kurang berpengalaman akan memperoleh hasil yang kurang memuaskan. (Purba, 2010).

\section{Tingkat Pendapatan}

Tabel 4. Persentase Tingkat Pendapatan

\begin{tabular}{|c|c|c|c|c|c|}
\hline \multirow{2}{*}{$\begin{array}{c}\text { Karakteristik } \\
\text { Petani }\end{array}$} & \multirow{2}{*}{ Kategori } & \multicolumn{2}{|c|}{ Buruh tani } & \multicolumn{2}{|c|}{ Petani penggarap } \\
\hline & & Responden (n) & Persen $(\%)$ & Responden (n) & Persen (\%) \\
\hline Tingkat & Rendah & 14 & $47 \%$ & 2 & $33 \%$ \\
\hline pendapatan & Tinggi & 16 & $53 \%$ & 4 & $67 \%$ \\
\hline
\end{tabular}

Di sini tingkat pendapatan dibagi dua baik untuk buruh tani dan petani penggarap, yaitu rendah antara Rp1.040.000,- hingga Rp1.672.948 yang adalah UMR Kota Garut, dan tinggi yaitu di atas UMR Kota
Garut. Tingkat pendapatan buruh tani stevia di Desa Mekarsari sebagian besar memiliki tingkat pendapatan yang rendah atau Rp1.040.000,- hingga Rp1.672.948,- (47\%) dan sebagian lagi yang tingkat 
pendapatannya tinggi atau di atas Rp1.672.948,- jumlahnya lebih sedikit (53\%). Tingkat pendapatan petani penggarap stevia di Desa Mekarsari mayoritas memiliki tingkat pendapatan tinggi (67\%) atau di atas Rp1.672.948,- dan sebagian lagi rendah antara Rp1.040.000,hingga Rp1.672.948,-.

\section{Analisis Tabulasi Silang Antara Karakteristik Petani dengan Persepsi Petani terhadap}

\section{Usahatani Stevia}

Analisis Tabulasi Silang Umur Petani dan Persepsi terhadap Usahatani Stevia

Tabel 5. Analisis Tabulasi Silang Umur Buruh Tani dan Persepsi terhadap Usahatani Stevia

\begin{tabular}{lcccc}
\hline & Umur & \multicolumn{2}{c}{ Buruh tani } & \multicolumn{2}{c}{ Petani penggarap } \\
\cline { 2 - 5 } Persepsi & Responden $(\mathrm{n})$ & Persen $(\%)$ & Responden $(\mathrm{n})$ & Persen $(\%)$ \\
\hline Sangat Baik & 5 & 19 & 0 & 0 \\
Baik & 13 & 50 & 4 & 00 \\
Kurang Baik & 7 & 27 & 0 & 0 \\
Tidak Baik & 1 & 4 & 0 & 0 \\
Sangat Tidak Baik & 0. & 0 & 4 & 100 \\
Total & 26 & 100 & & 81,76 \\
\hline Nilai Rataan Skor & \multicolumn{7}{c}{75,15} & & 0 \\
\hline
\end{tabular}

Persepsi buruh tani berumur produktif sebanyak $50 \%$ baik dan 19\% sangat baik, dari segi jumlah mayoritas persepsinya adalah positif terhadap usahatani stevia. Nilai rataan skornya sebesar 75,15 yang menunjukkan bahwa persepsi petani secara keseluruhannya terhadap usahatani stevia adalah baik. Sebanyak $100 \%$ buruh tani berusia tidak produktif berpresepsi baik, dari segi jumlah presepsinya adalah positif terhadap usahatani stevia. Nilai rataan skornya sebesar 81,76 yang menunjukkan persepsi terhadap usahatani stevia secara keseluruhannya adalah baik. Hasil ini menunjukkan bahwa baik buruh tani usia produktif maupun buruh tani usia tidak produktif sama-sama dapat dijadikan petani mitra bagi siapapun yang ingin mengajak bekerja sama jika dilihat dari persepsinya yang baik.

Tabel 1. Analisis Tabulasi Silang Umur Petani Penggarap dan Persepsi terhadap Usahatani Stevia

\begin{tabular}{lcccc}
\hline \multirow{2}{*}{ Persepsi } & Umur & \multicolumn{2}{c}{ Petani Penggarap Umur Produktif } & \multicolumn{2}{c}{ Petani Penggarap Umur Tidak Produktif } \\
\cline { 2 - 5 } & Responden $(\mathrm{n})$ & Persen $(\%)$ & Responden $(\mathrm{n})$ & Persen $(\%)$ \\
\hline Sangat Baik & 2 & 33 & 0 & 0 \\
Baik & 3 & 50 & 0 & 0 \\
Kurang Baik & 1 & 17 & 0 & 0 \\
Tidak Baik & 0 & 0 & 0 & 0 \\
Sangat Tidak Baik & 0 & 0 & 0 & 0 \\
Total & 6 & 100 & 0 & 0 \\
\hline Nilai Rataan Skor & & 80,39 & & \\
\hline
\end{tabular}


Petani penggarap yang masih berusia produktif ini memungkinkan mereka untuk cepat mengadopsi suatu teknologi baru dalam usahatani stevia jika suatu saat nanti ada teknologi baru. Sebanyak 50\% berpresepsi baik dan 33\% berpresepsi sangat baik, dari segi jumlah mayoritas petani penggarap memiliki presepsi positif terhadap usahatani stevia. Nilai rataan skornya adalah 80.39 yang menunjukkan persespi rata-rata petani penggarap terhadap usahatani stevia adalah baik.

\section{Analisis Tabulasi Silang Pengalaman Bertani Petani dan Persepsi terhadap Usahatani} stevia

Tabel 2. Analisis Tabulasi Silang Pengalaman Bertani Buruh Tani dan Persepsi terhadap Usahatani Stevia

\begin{tabular}{|c|c|c|c|c|c|c|}
\hline \multirow[t]{2}{*}{ Pengalaman } & \multicolumn{2}{|c|}{$\begin{array}{c}\text { Buruh Tani Berpengalaman } \\
\text { Rendah }\end{array}$} & \multicolumn{2}{|c|}{$\begin{array}{c}\text { Buruh Tani } \\
\text { Berpengalaman Sedang }\end{array}$} & \multicolumn{2}{|c|}{$\begin{array}{c}\text { Buruh Tani } \\
\text { Berpengalaman Tinggi }\end{array}$} \\
\hline & $\begin{array}{c}\text { Responden } \\
\text { (n) }\end{array}$ & Persen $(\%)$ & $\begin{array}{l}\text { Responden } \\
\text { (n) }\end{array}$ & Persen $(\%)$ & $\begin{array}{l}\text { Responden } \\
\text { (n) }\end{array}$ & Persen $(\%)$ \\
\hline Sangat Baik & 4 & 33 & 3 & 27 & 1 & 14 \\
\hline Baik & 6 & 50 & 5 & 46 & 3 & 43 \\
\hline Kurang Baik & 1 & 8 & 3 & 27 & 3 & 43 \\
\hline Tidak Baik & 1 & 9 & 0 & 0 & 0 & 0 \\
\hline Sangat Tidak Baik & 0 & 0 & 0 & 0 & 0 & 0 \\
\hline Total & 12 & 100 & 11 & 100 & 7 & 100 \\
\hline Nilai Rataan Skor & \multicolumn{2}{|c|}{76,76} & \multicolumn{2}{|c|}{76,26} & \multicolumn{2}{|c|}{74,45} \\
\hline
\end{tabular}

Persepsi buruh tani berpengalaman rendah sebanyak $50 \%$ baik dan $33 \%$ sangat baik, dari segi jumlah mayoritas persepsinya adalah positif terhadap usahatani stevia. Persepsi buruh tani berpengalaman sedang juga positif terhadap usahatani stevia karena memiliki jumlah mayoritas persepsi baik sebanyak $46 \%$ baik dan $27 \%$ sangat baik. Begitu pula dengan persepsi buruh tani berpengalaman tinggi, dengan $43 \%$ berpresepsi baik. Semua buruh tani dari berbagai lama pengalaman bertani memiliki persepsi baik terhadap usahatani stevia. Nilai rataan skor dari masing-masing lama pengalaman bertani juga menunjukkan persepsi yang baik terhadap usahatani stevia, yaitu untuk yang berpengalaman rendah memiliki nilai rataan skor 76,76 , berpengalaman sedang memiliki nilai rataan skor 76,26 , dan berpengalaman tinggi memiliki nilai rataan skor 74,45 . Hal ini karena buruh tani tanpa dipengaruhi berbagai lama pengalaman bertani melihat berbagai keuntungan dan kemudahan yang didapatkan dari berbagai aspek usahatani stevia.

Mayoritas petani penggarap stevia di Desa Mekarsari berpresepsi baik, yaitu 50\% berpresepsi sangat baik dan 25\% berpresepsi baik pada penggarap berpengalaman rendah, 100\% berpresepsi baik pada penggarap berpengalaman sedang dan $100 \%$ berpengalaman tinggi berpresepsi baik terhadap usahatani stevia. 
Nilai rataan skornya juga menunjukkan bahwa petani penggarap di Desa Mekarsari memiliki presepsi yang baik dengan nilai rataan skor 80 untuk yang berpengalaman rendah, 82,35 berpengalaman sedang, dan 83,14 pada yang berpengalaman tinggi, jadi semuanya berpresepsi baik dan nilai rataan skor bertambah tiap tingkatan pengalaman bertani. Petani yang sudah lama bertani akan lebih mudah menerapkan inovasi atau menerapkan anjuran penyuluhan dan penerapan teknologi daripada petani pemula atau petani baru (Soekartawi, 1994).

Tabel 3. Analisis Tabulasi Silang Pengalaman Bertani Petani Penggarap dan Persepsi terhadap Usahatani Stevia

\begin{tabular}{|c|c|c|c|c|c|c|}
\hline \multirow[t]{2}{*}{ Pengalaman } & \multicolumn{2}{|c|}{$\begin{array}{c}\text { Petani Penggarap } \\
\text { Berpengalaman Rendah }\end{array}$} & \multicolumn{2}{|c|}{$\begin{array}{c}\text { Petani Penggarap } \\
\text { Berpengalaman Sedang }\end{array}$} & \multicolumn{2}{|c|}{$\begin{array}{c}\text { Petani Penggarap } \\
\text { Berpengalaman Tinggi }\end{array}$} \\
\hline & $\begin{array}{l}\text { Responden } \\
\text { (n) }\end{array}$ & Persen $(\%)$ & $\begin{array}{l}\text { Responden } \\
\text { (n) }\end{array}$ & Persen $(\%)$ & $\begin{array}{l}\text { Responden } \\
\text { (n) }\end{array}$ & Persen $(\%)$ \\
\hline Sangat Baik & 2 & 50 & 0 & 0 & 0 & 0 \\
\hline Baik & 1 & 25 & 1 & 100 & 1 & 100 \\
\hline Kurang Baik & 1 & 25 & 0 & 0 & 0 & 0 \\
\hline Tidak Baik & 0 & 0 & 0 & 0 & 0 & 0 \\
\hline Sangat Tidak Baik & 0 & 0 & 0 & 0 & 0 & 0 \\
\hline Total & 0 & 0 & & 100 & 0 & 0 \\
\hline
\end{tabular}

Analsis Tabulasi Silang Tingkat Pendapatan Petani dan Persepsi terhadap Usahatani Stevia

Tabel 4. Analsis Tabulasi Silang Tingkat Pendapatan Buruh Tani dan Persepsi terhadap Usahatani Stevia

\begin{tabular}{lcccc}
\hline \multirow{2}{*}{ Pendapatan } & \multicolumn{2}{c}{ Buruh Tani Pendapatan Rendah } & \multicolumn{2}{c}{ Buruh Tani Pendapatan Tinggi } \\
\cline { 2 - 5 } Persepsi & Responden $(\mathrm{n})$ & Persen $(\%)$ & Responden $(\mathrm{n})$ & Persen $(\%)$ \\
\hline Sangat Baik & 2 & $9 \%$ & 3 & $37 \%$ \\
Baik & 12 & $55 \%$ & 5 & $63 \%$ \\
Kurang Baik & 7 & $31 \%$ & 0 & $0 \%$ \\
Tidak Baik & 1 & $5 \%$ & 0 & $0 \%$ \\
Sangat Tidak Baik & 0 & $0 \%$ & 0 & $0 \%$ \\
Total & 22 & $100 \%$ & 8 & $100 \%$ \\
\hline Nilai Rataan Skor & \multicolumn{3}{c}{}
\end{tabular}

Persepsi buruh tani yang memiliki pendapatan tinggi $100 \%$ adalah positif ke arah yang baik, karena $37 \%$ persepsi buruh tani berpendapatan tinggi adalah sangat baik, dan $63 \%$ persepsi buruh tani berpendapatan tinggi adalah baik. Persepsi buruh tani yang berpendapatan rendah tidak semua baik karena terdapat $5 \%$ yang berpresepsi tidak baik dan $31 \%$ yang kurang baik, namun mayoritas berpresepsi baik dengan $12 \%$ berpresepsi baik dan $9 \%$ berpresepsi sangat baik. Bila dibandingkan dari segi nilai rataan skor, persepsi buruh tani dengan pendapatan tinggi memiliki jauh lebih tinggi nilai rataan skor, yaitu 85,15 daripada buruh tani dengan pendapatan rendah yang memiliki nilai rataan skor 72,72. Seperti dikatakan oleh Soekartawi (1988: 93) bahwa petani berpenghasilan rendah lambat untuk 
melakukan difusi inovasi dan sebaliknya petani yang berpenghasilan tinggi mampu untuk melakukan percobaan-percobaan untuk perubahan.

Tabel 5. Analsis Tabulasi Silang Tingkat Pendapatan Petani Penggarap dan Persepsi terhadap Usahatani Stevia

\begin{tabular}{lcccc}
\hline \multirow{2}{*}{ Persepsi } & \multicolumn{2}{c}{ Petani Penggarap Pendapatan Rendah } & \multicolumn{2}{c}{ Petani Penggarap Pendapatan Tinggi } \\
\cline { 2 - 5 } & Responden $(\mathrm{n})$ & Persen $(\%)$ & Responden $(\mathrm{n})$ & Persen $(\%)$ \\
\hline Sangat Baik & 2 & $100 \%$ & 0 & $0 \%$ \\
Baik & 0 & $0 \%$ & 3 & $75 \%$ \\
Kurang Baik & 0 & $0 \%$ & 1 & $25 \%$ \\
Tidak Baik & 0 & $0 \%$ & 0 & $0 \%$ \\
Sangat Tidak Baik & 0 & $0 \%$ & 0 & $0 \%$ \\
Total & 2 & $100 \%$ & 4 & $100 \%$ \\
\hline Nilai Rataan Skor & \multicolumn{7}{c}{79,22} & & 76,76 & \\
\hline
\end{tabular}

Persepsi yang baik dari sisi biaya yang rendah karena biaya perawatan lebih rendah daripada biaya perawatan tanaman lain, dari penyemprotan obat hanya tiga kali dalam satu periode panen, dan satu kali pemupukan cor dalam sekali periode panen, serta pemupukan dasar hanya dilakukan satu kali dalam seumur hidup tanaman stevia. Nilai rataan skor petani penggarap berpendapatan rendah bernilai 79,22 dan petani berpendapatan tinggi bernilai 76,76 menunjukkan sama-sama baik. Hal ini menunjukkan baik petani penggarap berpendapatan rendah maupun petani penggarap berpendapatan tinggi dapat diberikan pinjaman dana yang lebih besar untuk mengembangkan usahatani stevianya karena baik petani penggarap berpendapatan tinggi maupun petani penggarap berpendapatan rendah akan mengembangkan usahatani stevianya dengan baik.

\section{Analisis Tabulasi Silang Tingkat Pendidikan dan Persepsi Petani Terhadap Usahatani}

\section{Stevia}

Tabel 11. Analisis Tabulasi Silang Tingkat Pendidikan dan Persepsi Buruh Tani Terhadap Usahatani Stevia

\begin{tabular}{|c|c|c|c|c|c|c|c|c|}
\hline \multirow[t]{2}{*}{ Pendidikan } & \multicolumn{2}{|c|}{$\begin{array}{c}\text { Buruh Tani Tingkat } \\
\text { pendidikan tidak tamat SD }\end{array}$} & \multicolumn{2}{|c|}{$\begin{array}{r}\text { Buruh Tani Tingkat } \\
\text { pendidikan tamat SD }\end{array}$} & \multicolumn{2}{|c|}{$\begin{array}{c}\text { Buruh Tani Tingkat } \\
\text { pendidikan tamat SMP }\end{array}$} & \multicolumn{2}{|c|}{$\begin{array}{c}\text { Buruh Tani Tingkat } \\
\text { pendidikan tamat SMA }\end{array}$} \\
\hline & $\begin{array}{l}\text { Responden } \\
\text { (n) }\end{array}$ & Persen (\%) & $\begin{array}{l}\text { Responden } \\
\text { (n) }\end{array}$ & Persen (\%) & $\begin{array}{l}\text { Responden } \\
\text { (n) }\end{array}$ & Persen (\%) & $\begin{array}{l}\text { Responden } \\
\text { (n) }\end{array}$ & Persen (\%) \\
\hline Sangat Baik & 1 & $14 \%$ & 1 & $7 \%$ & 1 & $34 \%$ & 0 & $0 \%$ \\
\hline Baik & 5 & $72 \%$ & 8 & $57 \%$ & 0 & $0 \%$ & 1 & $100 \%$ \\
\hline Kurang Baik & 1 & $14 \%$ & 5 & $36 \%$ & 1 & $33 \%$ & 0 & $0 \%$ \\
\hline Tidak Baik & 0 & $0 \%$ & 0 & $0 \%$ & 1 & $33 \%$ & 0 & $0 \%$ \\
\hline Sangat Tidak Baik & 0 & $0 \%$ & 0 & $0 \%$ & 0 & $0 \%$ & 0 & $0 \%$ \\
\hline Total & 6 & $100 \%$ & 14 & $100 \%$ & 3 & $100 \%$ & 1 & $100 \%$ \\
\hline Nilai Rataan Skor & \multicolumn{2}{|c|}{87,06} & \multicolumn{2}{|c|}{72,78} & \multicolumn{2}{|c|}{69,80} & \multicolumn{2}{|c|}{81,18} \\
\hline
\end{tabular}

Persepsi buruh tani terhadap usahatani stevia pada tingkat pendidikan dilihat dari jawaban buruh tani di seluruh tingkat pendidikan, mayoritas menunjukkan ke arah baik. Dilihat dari nilai rataan skor, semua angka nilai rataan skor pada seluruh tingkat pendidikan buruh tani menunjukkan mayoritas menunjukkan persepsi yang baik terhadap usahatani stevia. Usahatani stevia sangat sesuai bagi 
buruh tani dari berbagai macam tingkat pendidikan di Desa Mekarsari karena persepsi yang semuanya baik. Persepsi yang baik dari seluruh buruh tani dari berbagai tingkat pendidikan ini karena kemudahan untuk dimengerti dan mengaplikasikan cara-cara berbudidaya stevia, sehingga yang tidak tamat SD juga dapat menanamnya dengan mudah. Buruh tani dari berbagai macam tingkat pendidikan juga sama-sama bisa melihat hasil panen yang baik dari usahatani stevia.

Tabel 6. Analisis Tabulasi Silang Tingkat Pendidikan dan Persepsi Petani Penggarap Terhadap Usahatani Stevia

\begin{tabular}{|c|c|c|c|c|c|c|c|c|}
\hline \multirow[t]{2}{*}{ Pendidikan } & \multicolumn{2}{|c|}{$\begin{array}{l}\text { Petani Penggarap Tingkat } \\
\text { pendidikan tidak tamat SD }\end{array}$} & \multicolumn{2}{|c|}{$\begin{array}{l}\text { Petani Penggarap Tingkat } \\
\text { pendidikan tamat SD }\end{array}$} & \multicolumn{2}{|c|}{$\begin{array}{l}\text { Petani Penggarap Tingkat } \\
\text { pendidikan tamat SMP }\end{array}$} & \multicolumn{2}{|c|}{$\begin{array}{l}\text { Petani Penggarap Tingkat } \\
\text { pendidikan tamat SMA }\end{array}$} \\
\hline & $\begin{array}{l}\text { Responden } \\
\text { (n) }\end{array}$ & Persen (\%) & $\begin{array}{l}\text { Responden } \\
\text { (n) }\end{array}$ & Persen (\%) & $\begin{array}{l}\text { Responden } \\
\text { (n) }\end{array}$ & Persen $(\%)$ & $\begin{array}{l}\text { Responden } \\
\text { (n) }\end{array}$ & Persen $(\%)$ \\
\hline Sangat Baik & 0 & $0 \%$ & 1 & $34 \%$ & 1 & $50 \%$ & 0 & $0 \%$ \\
\hline Baik & 0 & $0 \%$ & 2 & $66 \%$ & 0 & $0 \%$ & 0 & 0 \\
\hline Kurang Baik & 0 & $0 \%$ & 0 & $0 \%$ & 1 & $50 \%$ & 0 & $0 \%$ \\
\hline Tidak Baik & 0 & $0 \%$ & 0 & $0 \%$ & 0 & $0 \%$ & 0 & $0 \%$ \\
\hline Sangat Tidak Baik & 0 & $0 \%$ & 0 & $0 \%$ & 0 & $0 \%$ & 0 & $0 \%$ \\
\hline Total & 0 & $0 \%$ & 3 & $100 \%$ & 2 & $100 \%$ & 0 & $100 \%$ \\
\hline
\end{tabular}

Menurut Prayitno (1986), Tingkat pendidikan akan mempengaruhi kemampuan responden untuk menerima inovasi yang diberikan. Semakin tinggi tingkat pendidikan, diharapkan pola berpikir semakin rasional. Hal ini sesuai dengan keadaan persepsi petani penggarap dari berbagai tingkat pendidikan terhadap usahatani stevia dilihat dari jumlah jawaban, mayoritasnya berpresepsi baik terhadap usahatani stevia. Dilihat dari nilai rataan skor, persepsi seluruh petani penggarap terhadap usahatani stevia adalah baik. Hal ini karena tingkat kerumitannya yang rendah karena kemudahan untuk berusahatani stevia dari aspek budidayanya yang mudah, kesesuaiannya dengan tingkat pendidikan mana pun, dan hasilnya yang menguntungan bagi petani penggarap dari seluruh tingkat pendidikan di Desa Mekarsari. Menurut Prayitno (1986),
Tingkat pendidikan akan mempengaruhi kemampuan responden untuk menerima inovasi yang diberikan. Semakin tinggi tingkat pendidikan, diharapkan pola berpikir semakin rasional.

\section{KESIMPULAN DAN SARAN}

\section{Kesimpulan}

1. Karakteristik petani di Desa Mekarsari petani penggarap seluruhnya masih berumur produktif dan buruh tani mayoritas juga masih berumur produktif (93\%). Tingkat pendidikan mayoritas adalah tamatan SD baik untuk petani penggarap (50\%) maupun buruh tani (53\%). Tingkat lama bertani untuk petani penggarap mayoritas adalah 1725 tahun $(50 \%)$ dan untuk buruh tani mayoritas adalah 7-19 tahun (40\%). Tingkat pendapatan mayoritas tinggi 
untuk petani penggarap (67\%) dan buruh tani (53\%).

2. Hasil analisis tabulasi silang menunjukkan persepsi buruh tani maupun petani penggarap dari karakteristik manapun, berpresepsi baik terhadap usahatani stevia, sehingga responden buruh tani dan petani penggarap di Desa Mekarsari bisa diajak untuk mengembangkan usahatani stevia. Persepsi yang baik ini dapat dilihat petani-petani lain dan dapat dijadikan acuan bagi mereka agar tertarik dan mau ikut serta juga dalam usahatani stevia di Desa Mekarsari.

\section{Saran}

1. Bagi pihak perusahaan selalu mendampingi para petani dan memberi arahan-arahan, serta bisa meningkatkan harga jual stevia dari petani untuk menjaga persepsi baik para petani penggarap dan buruh tani terhadap stevia.

2. Bagi kelompok tani Stevia Indonesia, melakukan kerjasama lebih banyak lagi dengan berbagai macam pihak yang memerlukan stevia sebagai produk jual atau bahan baku produk lain agar membuka peluang semakin luas bagi masyarakat Desa Mekarsari untuk matapencaharian dari usahatani stevia.

3. Bagi kelompok tani Stevia Indonesia bekerjasama dengan penyuluh desa melakukan penyuluhan lebih luas kepada masyarakat Desa Mekarsari mengenai usahatani stevia dan berbagai keuntungannya dari segi ekonomi dan kesehatan, agar persepsi petani dan buruh tani di Desa Mekarsari semakin baik lagi.

4. Pembebasan lahan Pamegatan milik PT Agrojabar yang dikuasai masyarakat segera diselesaikan agar janji perluasan lahan stevia hingga 100 hektar cepat terlaksana

\section{DAFTAR PUSTAKA}

Alisa, Ifa. 2007. Persepsi Petani Terhadap Inovasi Untuk Menggunakan Pupuk Kompos Kotoran Ternak Produk P4S Bumi Lestari Sragen (Kasus Petani di Desa Gondang Kecamatan Gondang Kabupaten Sragen). Skripsi. Program Studi Sosial Ekonomi Peternakan. Fakultas Peternakan. Institut Pertanian Bogor.

Geuns, J. M. C. 2003. Molecules of Interest Stevioside. Phytochemistry, 64 : 913921.

Mantra, I.B. 2004. Demografi Umum. Penerbit Pustaka Pelajar: Yogyakarta.

Prayitno, Hadi. 1986. Ekonomika Pembangunan, Edisi 1, Yogyakarta: BPFE.

Purba, Amir. 2010. Pengantar Ilmu Komunikasi. Medan.

Rakhmat, Jalaludin. 2004. Psikologi Komunikasi. Bandung: PT Rosdakarya, 51

Santoso, S., \& Tjiptono, F. (2001). Riset Pemasaran Konsep dan Aplikasi dengan SPSS. Elex Media Komputindo: Jakarta.

Soekartawi. 1988. Prinsip Dasar Manajemen Pemasaran Hasil Pertanian Teori dan Aplikasi. Jakarta: Rajawali Press. 